\title{
Uma Perspectiva de Análise sobre o Processo de Trabalho em Saúde: produção do cuidado e produção de sujeitos
}

\section{An Analysis Perspective on the Work Process in the Area of Health: the production of care and the production of subjects}

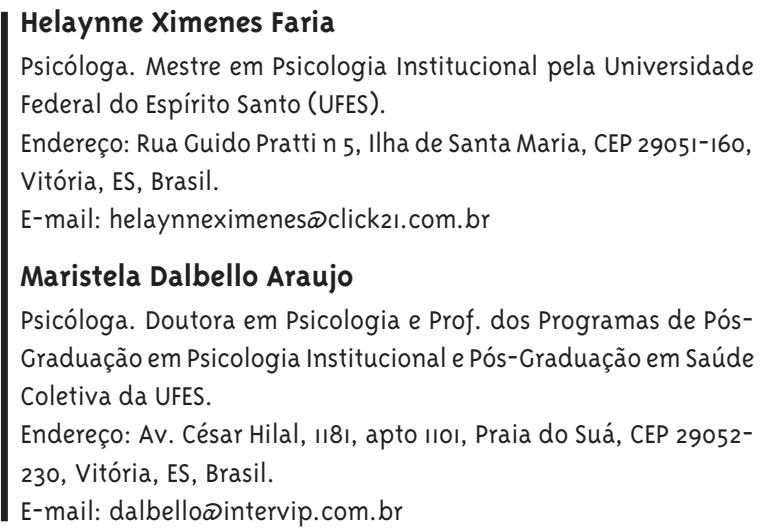

Resumo

Este artigo tem por objetivo apresentar uma perspectiva de análise sobre o processo de trabalho em saúde que o considera capaz de produção de procedimentos especializados e atos cuidadores, e também como um campo fértil para a produção de sujeitos protagonistas na construção de um sistema de saúde mais justo e de relações societais mais democráticas. Trata-se de uma reflexão teórica alimentada por pesquisas desenvolvidas em serviços de atenção básica na região da Grande Vitória. Aborda a centralidade do trabalho na construção do homem, ressaltando as especificidades do trabalho em saúde no seu aspecto relacional. Sugere que o processo de trabalho seja analisado sob a ótica do jogo de forças que se presentifica no cotidiano e valoriza os instrumentos e estratégias metodológicas que incluam os trabalhadores no questionamento daquilo que se produz cotidianamente. Nesse sentido, aponta a necessidade de construção de espaços coletivos de fala e reflexão sobre o trabalho com a presença da comunidade, de modo a avançar na construção de um novo senso comum que conceba a saúde não apenas como ausência de sintomas, mas como qualificação da existência.

Palavras-chave: Trabalho; Processo de Trabalho; Micropolítica; Protagonismo; Participação Comunitária. 


\section{Abstract}

The goal of this article is to present an analysis perspective on the work process in the area of health. This article understands that work is able to produce specialized procedures as well as caring acts. It also considers work as a fertile field for the production of subjects who are committed to the construction of a more just health system and more democratic social relationships. It promotes a theoretical reflection based on research developed in health care units in the Greater Vitória region (southeast of Brazil). The article approaches the centrality of work in man's construction, focusing on the singularities of work in health in terms of its relational aspects. It suggests that the work process should be analyzed in light of everyday struggling, and values the instruments and methodological strategies that include workers in the reflection on what is produced on a daily basis. In this sense, it shows the necessity of establishing opportunities for collective speech and reflection on work within the community, so that it is possible to enhance the construction of a new common sense which understands health not only as lack of symptoms, but also as the qualification of existence.

Keywords: Work; Work Process; Micropolitics; Commitment; Community Participation.

\section{Introdução}

Apresentamos uma perspectiva de análise do processo de trabalho que consiga visualizá-lo não apenas em sua capacidade de execução de procedimentos biomédicos, mas também como campo de invenção e experimentação de atos cuidadores. Apesar da realização de procedimentos técnicos pautados no saber científico, no cotidiano do trabalho em saúde podem ocorrer situações consideradas "não cuidadoras". Desse modo, entendemos que o cuidado envolve muito mais do que a realização de procedimentos, pois adotamos uma perspectiva ampliada de promover a defesa da vida e controlar os riscos de adoecimento. Sugerimos, assim, uma ampliação do objeto de trabalho proposto pelo modelo biomédico, já que valorizamos as singularidades e apostamos na autonomia dos sujeitos envolvidos na relação capaz de produzir cuidado.

Como o trabalho em saúde lida com a vida humana, envolve um grau de imprevisibilidade muito grande e a possibilidade de inúmeras formas de intervenção, retratando um mundo dinâmico, no qual as situações raramente se repetem. Nesse contexto, invenção e experimentação de práticas são necessárias, uma vez que a singularidade dos envolvidos deve ser levada em consideração nos atos executados no cotidiano dos serviços. Além disso, é primordial o questionamento ético a respeito dos efeitos dessas práticas. Assim, compreendemos que o trabalho em saúde, pressupõe interação entre sujeitos e é dependente das potencialidades instituintes dos encontros realizados nos serviços de saúde. Dessa forma, tomamos o trabalho como lócus privilegiado para a construção de novos saberes e de sujeitos protagonistas, no intercâmbio entre profissionais e comunidade.

Este artigo se baseia em reflexões teóricas provenientes da área das ciências sociais em saúde, especialmente da área da saúde e trabalho e em pesquisas realizadas sobre o tema Processo de trabalho e subjetividade, nas quais temos tido oportunidade de estudar os processos de trabalho engendrados na área da saúde, sobretudo no âmbito da Atenção Básica e do Programa de Saúde da Família (DalbelloAraujo, 2005; Passamani, 2006; Souza Cruz, 2007; Hoffmann, 2009; Iglesias, 2009; Silva, 2009; Faria, 2010). 


\section{A Importância no Trabalho na Construção do Sujeito}

A primeira das noções necessárias para a compreensão do argumento em questão diz respeito à centralidade do trabalho na construção do homem moderno. Muito já se escreveu sobre a importância do trabalho na socialização humana e para a construção do aparelho psíquico (Luria, 199o), sobre seu papel fundamental na elaboração cognitiva (Vygotsky, 1996, 1998), bem como na constituição do sujeito da modernidade. Desde o século XVII, o trabalho tem sido tratado como categoria central na compreensão da sociedade e das relações sociais, visto que elas são entendidas como desdobramentos das relações sociais de produção, regidas, em última instância, pelo trabalho humano. Ainda que a prudência imponha assinalar o risco que significa universalizar uma concepção e uma prática que só têm sentido no interior de configurações sociais e políticas específicas, ou seja, ainda que tenhamos cautela ao afirmar que o trabalho somente pode ser compreendido como essência do humano numa sociedade que assim o erigiu, é inegável o esforço político, ideológico, subjetivo e espiritual que fez emergir a categoria trabalho com tal força de significação, num descontínuo entre o mundo grego e o capitalismo (Gondar, 1989).

A significação do trabalho ligada a um valor vital e espiritual foi extremamente útil para fazer florescer a produção e o excedente que, dessa forma, pode ser trocado, acumulado, vendido. Além disso, todo esse movimento foi decisivo para a construção da racionalidade capitalista ocidental moderna (Weber, 1996). Pois bem, não se trata de valor natural, universal, ou a-histórico, porém é impossível deixar de ver a força de afirmação deste ethos entre todos os povos que se desenvolveram sob influência europeia, visto que muitos vetores foram colocados em sintonia para garantir o sucesso desse empreendimento, ou seja, colocar o trabalho como balizador das relações sociais.

Para Marx (1975), o trabalho é o motor de todos os processos sociais, a categoria chave na compreensão das relações sociais de produção e também para a compreensão do homem. E, ainda que hoje esteja em discussão a centralidade e não a categoria tra- balho para a compreensão das relações sociais (Offe, 1989, 1994), é este ponto de vista que pretendemos discutir, ou seja, a envergadura do trabalho como construtor do próprio homem (Jardim, 1997).

Marx (1975, p. 49) deixa clara a importância atribuída ao trabalho na história humana, em um trecho perfeitamente condizente com uma leitura materialista da história, ao afirmar que: "Atuando assim sobre a natureza externa e modificando-a, o homem ao mesmo tempo transforma sua própria natureza”. Podemos também mencionar os estudos de Engels (1974) sobre a importância da sociabilidade, da atividade, da comunicação e do trabalho para a evolução ou hominização dos humanos, quando este considera que "O trabalho, dizem os economistas, é a fonte de toda a riqueza. Mas é infinitamente mais. É a condição fundamental primeira de toda a vida humana, o trabalho criou o próprio homem" (p. 171).

No entanto, uma importante característica do modo capitalista de produção é a divisão técnica e social do trabalho, que sofreu intensa elaboração desde o fim do século XIX, por meio de estudiosos da atividade humana (Taylor, 1990), que sistematizaram a separação entre concepção e execução, sofisticada por inúmeras formas de controle e organização do trabalho fabril, o que acabou comprometendo o caráter humanizador do trabalho.

Braverman (1987) analisa as diversas maneiras pelas quais a organização do trabalho foi sendo adequada ao propósito de controle sobre a força de trabalho e a produção. Entretanto, críticas à desumanização das cadências infernais denunciadas pelo movimento sindical, além do alto custo e a baixa eficácia desse modo de organização do trabalho, dependente que é de inúmeros e dispendiosos meios de controles, levaram a transformações sociais que provocaram mudanças (Dejours, 1992). Em meados do século XX, com o advento do toyotismo, muitas linhas de montagem foram substituídas por ilhas de produção. Essas células ou ilhas deveriam produzir baseadas em trocas entre os membros, responsabilidade compartilhada e salários vinculados à produção - o controle então se torna mais econômico, pois todos são controladores uns dos outros (Dejours, 1993). Interessa-nos frisar que esse modo de organizar o processo de trabalho de forma parcializada e fragmentada é fruto de um paradigma 
epistemológico e societal (Santos, 200o). Portanto, sua influência no modo de organizar o trabalho não se restringiu às fábricas, permeando o sistema de ensino e demais atividades sociais. Assim, essa forma de organizar o processo de trabalho também é característica dos serviços de saúde, apesar de suas especificidades (Pires, 1996).

\section{Especificidade do Trabalho em Saúde}

O trabalho em saúde traz algumas peculiaridades que gostaríamos de abordar. Trata-se de um mundo complexo, dinâmico e criativo, no qual o trabalho prescrito e o trabalho real se confrontam cotidianamente. A distinção entre trabalho prescrito e trabalho real é uma noção-chave para a Ergonomia Francesa (Laville, 1977; Wisner, 1987; Dejours, 1993). Refere-se a uma série de manobras, desvios de regras, flexibilização de normas, acertos e jeitos próprios (savoir faire) que cada operador coloca em ação, por meio da comunicação e acordos entre pares ou pela sua própria inteligência astuciosa para que a tarefa possa acontecer e o trabalho possa ser realizado a contento. Desse modo, trabalho prescrito refere-se a tudo aquilo que está posto de antemão (normas, tempo gasto na operação, modo de utilizar ferramentas) e o trabalho real é aquele que acontece efetivamente no cotidiano, longe das condições ideais e idealizadas pelos administradores. Os autores citados apontam que essa defasagem entre o trabalho real e o prescrito ocorre também em países fortemente industrializados e mesmo naqueles setores clássicos de produção, nos quais a tradição taylorista foi levada aos extremos, de maneira a manter o afastamento entre atividades que envolvam a concepção, a cargo da gerência que prescreve as tarefas, e as de execução a cargo dos operadores que realizam efetivamente o trabalho. Essa constatação é ainda mais verdadeira quando observamos o processo de trabalho pertencente ao setor de serviços, como é o caso do trabalho na área da saúde, especialmente em Unidades Básicas de Saúde analisadas por meio de pesquisas sobre o desenvolvimento do cotidiano de trabalho (Dalbello-Araujo, 2005; Passamani, 2006; Hofmann, 2009).

Além da imprevisibilidade, característica do trabalho em saúde, que o torna refratário à prescrição de tarefas padrão, nessa área a produção se corporifica em um encontro entre pessoas. Desta forma, compreendemos que o processo de trabalho em saúde é inteiramente dependente da relação entre sujeitos, sendo assim, um trabalhador isolado é incapaz de executar as ações em saúde, cuja produção se realiza no espaço partilhado com o usuário (Merhy, 2002). É a partir do encontro que haverá a possibilidade de construções que possam ter impactos positivos nos problemas de saúde, no sentido de que tais construções pressupõem a inter-relação dos envolvidos. Desse modo, entendemos que a matéria prima do trabalho em saúde é o encontro, o que implica que a produção se executa entre trabalhador e usuário. No momento que se encontram, ambos devem atuar para possibilitar respostas positivas diante dos problemas de saúde. Torna-se imprescindível, portanto, o vínculo, o envolvimento e co-participação entre esses sujeitos. Nesse sentido, é primordial acolher as singularidades, ou seja, o original e criativo que emerge dos encontros, e perceber que ambos - profissional e usuário - são sujeitos ativos do processo da produção de saúde.

Entretanto, com o intuito de aumentar os controles sobre o ato do trabalho, há uma tentativa de que esses elementos sejam coisificados - tanto o profissional, quanto o usuário e a relação entre eles. Observa-se um aumento nas investidas de construção regulatória, postulado pela lógica da qualidade total, cujo foco nuclear é a fiscalização da oferta de serviços, melhorando assim as formas tradicionais de avaliação e controle. Há uma busca pelo estabelecimento de modelos em todos os níveis de atenção à saúde, o que denota uma aspiração regulatória imposta verticalmente, que se materializa em protocolos de ação, competências profissionais $a$ priori e procedimentos padronizados que se dirigem às partes de um corpo sem história e sem emoção, sem lugar contextualmente circunscrito ou culturalmente perpassado.

As análises realizadas, entretanto, afirmam que apesar das tentativas de reificação presentes no cotidiano dos serviços de saúde, o plano das subjetividades insiste e irrompe a todo instante, a alteridade é inevitável no ato de cuidar. Por mais que muitos profissionais se revistam de "invólucros impermeabilizantes" para fugir ao contato, este é 
sempre necessário no trabalho em saúde, provocando efeitos diversos nos envolvidos. (Dalbello-Araujo, 2005; Iglesias e col., 2009).

Muito frequentemente, estudos sobre o tema do trabalho em saúde afirmam que a relação profissional-paciente é permeada pela dor do paciente e também pelo sofrimento dos profissionais de saúde (Pitta, 1996). Compartilhamos esse entendimento e acrescentamos que esse cotidiano de trabalho, além disso, é composto de encontros subjetivos e embates de interesses. Embora a unidade de análise comumente recaia sobre a materialidade do encontro singular entre trabalhador e usuário, é preciso frisar que esse encontro é atravessado por saberes múltiplos. Tanto emanam do profissional como daquele que busca o serviço e, acima de tudo, do contexto que atravessa a relação entre eles: valores, crenças e as instituições que permeiam a vida em sociedade como a escola, a família, a TV, a pesquisa científica, a indústria farmacêutica, o mercado.

$\mathrm{Na}$ área da saúde ainda sobressaem modelos de gestão baseados na racionalidade técnico-burocrática. Modelos que se pautam por ordenações tempoespaciais, muitas vezes regulados em protocolos de ação decididos verticalmente, ou centrados em procedimentos médicos. Esses modelos de gestão optam por arranjos organizacionais em que cada um ocupa seu lugar, seu setor, ou seja, cada um tenta preencher totalmente os requisitos de seu papel profissional, repleto de competências, de forma disciplinada, organizada, pautada em comunicações verticais hierarquizadas e horizontais corporativas. Entretanto, como relatam Cecílio e Mendes (2004), nem sempre as coisas funcionam como o previsto em normas e diretrizes dos serviços de saúde, visto que sempre há reinterpretações e reinvenções por parte dos trabalhadores, que, exercendo suas possibilidades de autonomia, reconstroem dinâmicas e práticas no cotidiano de trabalho. Exatamente porque nada funciona como os administradores esperam, muitas vezes, em uma mesma Unidade Básica de Saúde, coexistem formas distintas de produção de cuidado. E assim convivem diferentes perspectivas de olhar para o processo de trabalho, para os produtores e para o que se espera sejam os produtos: cura, reabilitação e promoção da saúde.

Ao concordarmos com Marx (1975) e Engels
(1974) que o trabalho tem o poder de transformar os homens, precisamos encarar essa atividade humana de outra maneira, insistindo na premissa de que o trabalho em saúde, ao mesmo tempo em que produz cuidado, produz cuidadores. Nesse sentido, é fundamental gerar instrumentos analíticos que nos permitam verificar que o mesmo processo que produz saúde é capaz de criar profissionais mais saudáveis, e que ao mesmo tempo em que se fabrica o cuidado podemos tecer sujeitos de emancipação mais capazes de lutar pela própria saúde e a dos outros.

Para analisar o modo como o trabalho em saúde se organiza para atingir seu fim - a produção do cuidado - é necessário atentar para o fato de que estamos diante de um terreno bastante complexo (Merhy, 2004). Na área da saúde, estabelecem-se tensões, instabilidades e incertezas entre as políticas e organizações fortemente instituídas. Porém, nela também atuam forças instituintes que engendram novos arranjos e modos de "fabricar a saúde", especialmente no Brasil, em que o Sistema Único de Saúde (SUS) é fruto de forças sociais que se organizaram em torno do Movimento da Reforma Sanitária.

o SUS foi constituído por meio de embates de forças, enfrentando avanços e recuos até se instituir na forma atual e mantém-se em constante variação, principalmente no cotidiano dos serviços, haja vista a tensão advinda de interesses conflitantes e a influência de forças políticas, subjetivas, econômicas e sociais. A conquista do "direito à saúde", consignado na constituição de 1988, continua a exigir um amplo campo de forças em movimento em torno da construção de um sistema de saúde realmente universal e equânime. Dessa forma, Merhy (1999), compreendendo o jogo de forças entre o instituído (aquilo que está posto) e o instituinte (força que cria o novo) como gerador de potentes e novas configurações, assinala que o modo de se organizar a gestão do trabalho em saúde não pode ser baseado eficazmente nos modelos clássicos administrativos.

O trabalho em saúde tem base relacional e se dá através de jogos intersubjetivos. Dentro dessa perspectiva, Merhy (2002), baseado nas ideias de Ricardo Bruno Mendes Gonçalves (1994), descreve três tipos de tecnologias existentes em um processo de trabalho: as tecnologias duras, em que o trabalho já 
se encontra dado e cristalizado nelas mesmas, como máquinas e equipamentos; as tecnologias chamadas de leve-duras, que possuem duplo aspecto, de um lado, referem-se a saberes estruturados de determinada ocupação profissional, de outro, relacionam-se aos modos como esse trabalhador organiza o seu trabalho, de acordo com suas experiências pessoais e seus saberes próprios; e as tecnologias leves, que se presentificam no momento que o trabalhador se relaciona com o usuário, indicando falas, escutas, interpretações, acolhimentos, responsabilizações, vínculos, etc. Para esse autor, o trabalho vivo, que é o trabalho em ato, em ação, acontece no momento em que o trabalhador faz uso de saberes e práticas consagradas somadas à sua atividade criadora. Nesse tipo de análise, reconhece-se o aspecto instituinte e o autogoverno do trabalhador durante sua atividade. Afirma-se que, no momento que o profissional atua, se observa uma interação e se pode notar a autonomia do trabalhador ao organizar as ferramentas com os dados obtidos e os saberes próprios de sua profissão, levando-o ao raciocínio clínico, a decisões e ao tratamento.

Essas especificidades do trabalho em saúde se mostram no momento do encontro do profissional com o usuário. Esse momento, seguindo o raciocínio de Merhy (2002), é constituído por tecnologias leves que se manifestam quando há a interação entre os sujeitos. Essas tecnologias permitem produzir relações, construção, ou não, de acolhimentos, vínculos, responsabilizações, jogos transferências e construção de outros saberes. Sobre esse assunto, Merhy (200o) relata que o trabalhador de saúde opera três tipos de "valises" tecnológicas para atuar quando interage com o usuário: a "valise” da mão, que são as tecnologias duras; a "valise" da cabeça, ou as tecnologias leve-duras e a "valise" que só tem materialidade em ato, no momento da interação do trabalhador com o usuário, que é a valise do espaço relacional, referindo-se às tecnologias leves. Para esse autor, o arranjo entre essas "três valises", isto é a predominância da lógica instrumental ou relacional, determina diferentes perfis de assistência (Merhy, 2002), mas é no espaço relacional e no encontro que reconhecemos a singularidade do processo de trabalho como capaz de produzir cuidado. Nesse sentido, compreendemos que é essa leveza, esse espaço relacional, que distingue o trabalho no campo dos serviços, especificamente o de saúde, de outros tipos de produção, como o trabalho fabril. Esse contato, esses jogos relacionais demonstram a complexidade do processo que estamos estudando. Daí decorre a afirmação de Merhy, compartilhada por nós, de que o processo de trabalho em saúde deva ser analisado como "trabalho vivo em ato", isto é:

Um encontro entre pessoas que atuam uma sobre a outra, e no qual, opera um jogo de expectativas e produções, criando-se intersubjetivamente alguns momentos interessantes como momentos de falas, escutas e interpretações, no qual a produção de uma acolhida ou não das intenções que estas pessoas colocam neste encontro; momentos de possiveis cumplicidades, nos quais pode haver a produção de uma responsabilização em torno do problema que vai ser enfrentado, ou mesmo de momentos de confiabilidade e esperança, nos quais se produzem relações de vínculo e aceitações (Merhy, 1999, p. 308).

De acordo com a conceituação marxista sobre trabalho vivo e trabalho morto, trazida por Merhy (2002) ao campo dos estudos sobre o trabalho em saúde, compreendemos que o trabalho vivo se refere ao ato criativo, ao momento da produção no qual o trabalhador utiliza o seu potencial inventivo para dar materialidade ao objetivo de seu trabalho. O trabalho morto se configura como conjunto de elementos já dados que exercem sobre a produção uma forma rígida. Corresponde, por exemplo, às regras e exigências existentes como projetos, normas, exigências, organização de uma linha de produção, etc. A análise pormenorizada dos processos de trabalho nos faz afirmar que há processos produtivos nos quais a dimensão do trabalho vivo é maior do que a do trabalho morto, e outros que se manifestam de modo contrário, ou seja, processos de captura do trabalho vivo pelo trabalho morto. Assim o coeficiente entre protagonismo/liberdade ou protagonismo/reprodução se dá no mundo geral da produção, tanto na conformação tecnológica dos atos produtivos, quanto dos modos de governálos. Onde há trabalhadores produzindo, há essa polarização, independente do que se produz, e isso ocorre em todos os setores produtivos (Merhy, 2002). 
Essa captura sempre foi um dos objetivos do modo taylorista de organizar o trabalho, que percebe esse autogoverno do trabalhador e busca em parte domesticá-lo para otimizar as linhas de produção de acordo com os moldes clássicos das empresas. As mudanças tecnológicas se fazem com a criação de novas maquinarias e novas tecnologias de controle que visam “[...] garantir a 'captura' do trabalho vivo em ato na produção, permitindo que os autogovernos tenham de ser coerentes com a natureza do processo produtivo capitalista” (Merhy, 1997, p. 95).

O que temos percebido em nossos estudos é que na área da saúde, especialmente na Atenção Básica, ainda que existam procedimentos formatados e prescritos, como, por exemplo, os protocolos de recepção e atendimento, o trabalhador da saúde ainda tem conseguido exercer esse autogoverno. No transcurso de seu cotidiano ele toma várias decisões durante o seu encontro com o usuário. Na maioria das vezes, pode intervir no modo de receber o usuário para além do que está normatizado e protocolado como modo de atuar, conseguindo alterar claramente o conteúdo de uma dada etapa do processo de trabalho ou mesmo de todo o processo. Notamos, portanto, que a captura total do autogoverno nas práticas em saúde não só é muito difícil e restrita, mas impossível, por sua própria característica. Assim, num estabelecimento de saúde, encontramos uma dinâmica bastante complexa ao se considerar o conjunto de autogovernos em operação, os jogos de interesses organizados como forças sociais, que atuam na micropolítica do processo de trabalho. Por isso, ao pensar a gestão do trabalho, deve-se estar atento ao fato de estarmos lidando com um campo de forças em conflito e jogos de interesse presentificados.

Também percebemos nas análises do cotidiano de trabalho que nem sempre o trabalho em saúde opera produtos como "atos cuidadores". Nem sempre a dimensão cuidadora, focalizada nas necessidades e desejos dos usuários consegue se expressar. Há rotinas centradas em procedimentos (Franco, 2003), ou seja, baseadas em procedimentos fortemente arraigados na prática que pouco sentido fazem no que se diz respeito às reais necessidades dos usuários.

Assim, sugerimos que o processo de trabalho seja analisado sob a ótica do jogo de forças que se presentifica no cotidiano, em sua dimensão macro e micro- política e valorizamos os instrumentos e estratégias metodológicas que incluem os trabalhadores no questionamento do que se produz cotidianamente, tais como: as entrevistas coletivas (Dalbello-Araujo, 2008) e o uso dos mapas analíticos (Franco e Merhy, 2007). Esses espaços se constituem momentos de pesquisa, e especialmente espaços coletivos de fala e reflexão sobre o trabalho em saúde. Ressaltamos a importância da participação da comunidade nesses momentos, de modo a avançar na construção de um novo senso comum que conceba a saúde não apenas como ausência de sintomas, mas como qualificação da existência por meio da emancipação psicossocial (Santos, 2000).

Entretanto, é necessário, estabelecer algumas ponderações sobre os limites e possibilidades ao incluir-se a comunidade nas estratégias de emancipação. Para isso, retomamos a postura crítica de Bauman (2003). Para esse autor, há um fascínio saudosista impregnado na ideia de "comunidade", palavra que carrega a ideia de que, em comunidade todos se entendem bem, são confiáveis e acolhedores entre si, sugerindo ajuda mútua. Com essas ressalvas, insistimos na necessidade de sua inclusão, porém sugerimos tomar a comunidade como algo concreto e real, em que existem tensões, diferenças e conflitos. Para Baumam (2003), nenhum problema pode ser resolvido de antemão, portanto, cabe aos interessados na construção de uma sociedade mais justa a elaboração de projetos que contemplem a flexibilidade necessária no enfrentamento e resolução de problemas locais e inesperados.

Assim nos aproximamos das virtualidades das comunidades ampliadas de discussão postuladas por Santos (200o), que assinala a necessidade de um esforço empreendido na comunidade, no sentido de construir ideias comuns, não à custa do consenso fechado, conseguido sob a ditadura das necessidades, mas incentivando o exercício da comunicação livre, em que todos participam com igual poder e competência argumentativa no processo de ressignificação da vida social. O restabelecimento das potencialidades epistemológicas da comunidade exige, entretanto, uma radical transformação do modelo herdado e dominante de conceber e avaliar a vida. Desse modo, por meio da procura de categorias globais de inteligibilidade, poderemos construir 
projetos locais emancipatórios (Dalbello-Araujo e Andrade, 2007).

Entendendo as ações em saúde como um campo de lutas em defesa da vida, podemos compreender a importância da invenção social de um novo conhecimento emancipatório. A racionalidade científica prepondera no interior das práticas médico-sanitárias, ou seja, está presente em sua constituição desde suas origens, dando-lhes sustentação e legitimidade. Devido a essa constatação devemos estar atentos e incentivar as situações e estratégias que potencializam a construção do conhecimento emancipação, buscando subsidiar a comunidade e os trabalhadores da saúde com os instrumentos e meios para a construção de comunidades argumentativas ampliadas, úteis para a criação de um novo senso comum (Dalbello-Araujo, 2005).

Não há dúvida de que o movimento social emancipatório, representado pelo Movimento da Reforma Sanitária, foi competente para formular outro Sistema de Saúde para nosso país, calcado na universalidade, na participação e na busca de equidade. Porém, há um longo caminho a se trilhar, muito a ser feito para que possamos ir em direção a um conhecimento emancipatório que contribua para a transformação das desigualdades sociais (Dalbello-Araujo e Andrade, 2007).

Desse modo, estamos empenhados na construção desses espaços, lugares de discussão e produção de sujeitos mais autônomos na produção de seu trabalho. Sujeitos com capacidade de análise e de intervenção. Em última instância, objetivamos o aumento da democracia institucional, a construção de espaços coletivos - arranjos concretos de tempo e lugar, em que o poder esteja em jogo, e onde, de fato, se analisem problemas e se tomem deliberações; espaços onde haja a explicitação de interesses divergentes e negociações, construção de consensos, formação de compromisso e construção de contratos (Campos, 2000).

Nesse sentido, o exercício da política no âmbito do trabalho, nas instituições encarregadas de promover saúde e produzir o cuidado é um exercício de afirmação das diferenças e da vida. Hoje essas configurações têm sido qualificadas com diferentes nomenclaturas. Porém, em sua maioria, o processo de trabalho é destacado como o eixo da discussão.
Entendemos que é no cotidiano do processo do trabalho vivo que se operam as oscilações de poder, as mudanças de postura e é também nesse espaço que se constroem as possibilidades de invenção de outros fazeres. Daí a importância da urgência de sua alteração, visando a atingir a propagada reversão do modelo de assistência. Assim, estamos dando ênfase aos aspectos micropolíticos do trabalho vivo: "O desafio é buscar [...] outro modo de operar o trabalho em saúde e criar solidariedade entre eles [os profissionais] e a comunidade" (Merhy, 1997, p. 126). Esse intercâmbio de ideias e interlocução de sentidos podem nos ajudar a inventar novas formas de entender o que é saúde, vista como o elemento capaz de contribuir para a construção de uma nova forma de regulação social almejando a emancipação da vida (Santos, 2004).

Atualmente, percebemos a existência de dificuldades na relação dos profissionais com os usuários, um clima de tensão e de ameaça mútua (DalbelloAraujo, 2005). No entanto, é inegável que um processo de transformação está em curso, que algo novo se insinua pelos discursos surrados. A comunidade está participando da construção do SUS não apenas nos moldes previstos em lei, não de maneira eficiente e disciplinada. Participa porque produz tensão, gera conflito, exige mudança de posturas. 0 resultado ainda não está claro, mas as possibilidades de mudança estão postas e em alguns momentos se materializam em atos. Por isso é preciso:

\section{[...] dar visibilidade e procurar compreender o} papel desempenhado pela comunidade nesse embate de forças, visto que ela não se reduz ao lugar de receptáculo, mas acontece como sujeito ativo, mesmo quando esta ação é visível apenas em sua resistência às ordens médicas (DalbelloAraujo e Andrade, 2007, p.53)

É fundamental que haja tempo e espaço para compreender o que têm a dizer os novos atores dessa trama e, em contrapartida, que os profissionais estejam preparados para escutar. A presença do profissional na comunidade, na casa das pessoas, nos barracões comunitários, no salão de festas da Igreja, provoca questionamentos das partes. Pode trazer mudanças consistentes, tanto na maneira de a população enxergar o trabalho desses profissionais, 
quanto no modo de o profissional compreender o fenômeno da saúde/doença.

0 excesso de racionalidade técnica levou a um aumento exacerbado de especialismo, entretanto, certamente, outra racionalidade nos levará a tomar a comunidade como parte dessa rede produtora de cuidado e promotora de saúde. A racionalidade estéticoexpressiva proposta por Boaventura Souza Santos (200o) nos instiga a valorizar a forma simples de pensar os problemas, expressas pelo senso comum que é prático e pragmático e se reproduz colado às trajetórias e às experiências de vida de dado grupo social. São então os sujeitos ativos, portadores de conhecimento e prenhes de criatividade - trabalhadores e membros da comunidade - os produtores da saúde. São esses homens e mulheres os habilitados e capazes de gerar cuidado. Não por mágica, mas por afirmação de potência da vida.

\section{Referências}

BAUMAM, Z. Comunidade: a busca por segurança no mundo atual. Rio de Janeiro: Zahar, 2003.

BRAVERMAN, H. Trabalho e capital monopolista: a degradação do trabalho no século XX. 3. ed. Rio de Janeiro: Ed.Guanabara, 1987.

CAMPOS, G. W. S. Um método para análise e cogestão de coletivos. São Paulo: Hucitec, 2000.

CECILIO, L. C. O.; MENDES, T. C. Propostas alternativas de gestão hospitalar e o protagonismo dos trabalhadores: por que as coisas nem sempre acontecem como os dirigentes desejam? Saúde e Sociedade, São Paulo, v. 13, n. 2, p. 39-55, 2004.

DALBELLO-ARAUJO, M. D. O cotidiano de uma equipe do Programa de Saúde da Família: um olhar genealógico sobre o controle social. 2005. Tese (Doutorado em Psicologia) - Universidade Federal do Espírito Santo, Vitória, 2005.

DALBELLO-ARAUJO, M. Comunidade ampliada de pesquisa. In: ROSA, E. M.; SOUZA, L.; AVELLAR, L. Z. (Org.). Psicologia social: temas em debate. Vitória: ABRAPSO, 2008. p. 109-126.
DALBELLO-ARAUJO, M.; ANDRADE, A. N. Política, comunidade e controle social. In: ROSA, E. et al (Org.). Psicologia e saúde: desafios às políticas públicas no Brasil. Vitória EDUFES, 2007. p. 45-75. DEJOURS, C. A loucura do trabalho: estudos de psicopatologia do trabalho. São Paulo: CortezOboé, 1992.

DEJOURS, C. Inteligência operária e organização do trabalho. In: HIRATA, H. (Org.). Sobre o "modelo" japonês. São Paulo: Editora da Universidade de São Paulo, 1993. p. 281-311.

ENGELS, F. O papel do trabalho na transformação do macaco em homem. In: Dialéctica da natureza. Lisboa: Editorial Presença; São Paulo: Livraria Martins Fontes, 1974. p. 171-186.

FARIA, H. X. No fio da navalha: o processo de trabalho de uma unidade de saúde da família de Vila Velha-ES. 2010. Dissertação (Mestrado em Psicologia Institucional) - Universidade Federal do Espírito Santo, Vitória, 2010.

FRANCO, T. B. Processos de trabalho e transição tecnológica na saúde: um olhar a partir do Sistema Cartão Nacional de Saúde. 2003. Tese (Doutorado em Saúde Coletiva) - Faculdade de Ciências Médicas da Universidade Estadual de Campinas, Campinas, 2003.

FRANCO, T. B.; MERHY, E. E. Mapas analíticos: um olhar sobre a organização e seus processos de trabalho. Rio de Janeiro: Universidade Federal do Rio de Janeiro, 2007. Disponível em: < http://www. medicina.ufrj.br/micropolitica/textos/mapas_ analiticos.pdf >. Acesso em: 8 maio 2008.

GONÇALVES, R. B. M. Tecnologia e organização social da prática de saúde. Campinas: Hucitec, 1994.

GONDAR, J. O. O trabalho como objeto histórico. Cadernos do NUPSO, Rio de Janeiro, v. 2, n. 3, p. 20-32, 1989.

HOFFMANN, C. Acolhimento na atenção básica: navegações e mergulhos nos discursos e práticas produzidos no cotidiano de uma Unidade de Saúde da Família. 2009. Dissertação (Mestrado em Psicologia Institucional) - Universidade Federal do Espírito Santo, Vitória, 2009. 
IGLESIAS, A. Em nome da promoção à saúde: análise das ações em unidade de saúde da macrorregião de Maruípe Vitória - ES. 2009. Dissertação (Mestrado em Saúde Coletiva) -Universidade Federal do Espírito Santo, Vitória, 2009.

IGLESIAS, A. et al. Análise das ações de promoção à saúde realizadas por psicólogos do município de Vitória-ES. Psicologia: Teoria e Prática, São Paulo, v. 11, n. 1, p. 110-127, 2009.

JARDIM, S. O trabalho e a construção do sujeito. In: SILVA-FILHO, J. F.; JARDIM, S. (Org.). $A$ danação do trabalho. Rio de Janeiro: Te corá Editora, 1997.

LAVILLE, A. Ergonomia. São Paulo: Editora da Universidade de São Paulo, 1977.

LURIA, A. R. Desenvolvimento cognitivo: seus fundamentos culturais e sociais. São Paulo: Ícone, 1990.

MARX, K. O capital. São Paulo: Difel, 1975. Livro I, v. l.

MERHY, E. E. Em busca do tempo perdido: a micropolítica do trabalho vivo em saúde. In: MERHY, E. E; ONOCKO, R. (Org.). Agir em saúde: um desafio para o público. São Paulo: Hucitec. 1997.

MERHY, E. E. $\mathrm{O}$ ato de governar as tensões constitutivas do agir em saúde como desafio permanente de algumas estratégias gerenciais. Ciência \& Saúde Coletiva, Rio de Janeiro, v. 4, n. 2. p. 305-314, 1999.

MERHY, E. E. Um ensaio sobre o médico e suas valises tecnológicas: contribuições para compreender as reestruturações produtivas do setor saúde. Interface, Botucatu, v. 4, n. 6, p. 109116, 2000.

MERHY, E. E. Saúde: cartografia do trabalho vivo. São Paulo: Hucitec, 2002.
MERHY, E. E. $O$ ato de cuidar: a alma dos serviços de saúde. In: BRASIL. Ministério da Saúde. Secretaria de Gestão do Trabalho e da Educação na Saúde. Departamento de Gestão da Educação na Saúde. Ver - SUS Brasil: cadernos de textos. Brasília, DF, 2004. p. 108-137. (Série B - Textos Básicos de Saúde). Disponível em: <http://paginas. terra.com.br/saude/merhy/>. Acesso em: 10 maio 2008.

OFFE, C. Trabalho e sociedade. Rio de Janeiro: Tempo Brasileiro, 1989. v. 1.

OFFE, C. Capitalismo desorganizado. São Paulo: Brasiliense, 1994.

PASSAMANI, J. D. Programa Saúde da Família em Jardim da Penha: construção do acesso em um território de classe média. 2006. Dissertação (Mestrado em Saúde Coletiva) -Universidade Federal do Espírito Santo, Vitória, 2006.

PIRES, D. Processo de trabalho em saúde, no Brasil, no contexto das transformações atuais na esfera do trabalho: estudo em instituições escolhidas. 1996. Tese (Doutorado em Sociologia)

- Departamento de Sociologia do Instituto de Filosofia e Ciências Humanas da Universidade Estadual de Campinas, Campinas, 1996.

PITTA, A. Hospital: dor e morte como ofício. São Paulo: Hucitec, 1996.

SANTOS, B. de S. Para um novo senso comum: a ciência, o direito e a política na transição paradigmática. In:_____. A crítica da razão indolente: contra o desperdício da experiência. São Paulo: Cortez, 20oo. v. 1, p. 15-415.

SANTOS, B. de S. (Org.). Conhecimento prudente para uma vida decente: um discurso sobre as ciências revisitado. São Paulo: Cortez, 2004. SILVA, R. C. D. O cotidiano como produtor de vínculos: o caso da USF Santa Martha, Vitória-ES. 2009. Dissertação (Mestrado em Saúde Coletiva) - Universidade Federal do Espírito Santo, Vitória, 2009. 
SOUZA CRUZ, S. C. O processo de implantação

da Estratégia de Saúde da Família: o caso de Resistência, Vitória/ES. 2007. Dissertação (Mestrado em Saúde Coletiva) - Universidade Federal do Espírito Santo, Vitória, 2007.

TAYLOR, F. W. Princípios de administração científica. 8. ed. São Paulo: Atlas, 1990.

VYGOTSKY, L. S. A formação social da mente. Rio de Janeiro: Martins Fontes, 1996.

VYGOTSKY, L. S. Pensamento e linguagem. Rio de Janeiro: Martins Fontes, 1998.

WEBER, M. A ética protestante e o espírito do capitalismo. São Paulo: Pioneira, 1996.

WISNER, A. Por dentro do trabalho: ergonomia método e técnica. São Paulo: FTD: Oboré, 1987. 